\title{
Increasing prevalence of asthma diagnosis and symptoms in children is confined to mild symptoms
} G Ng Man Kwong, A Proctor, C Billings, R Duggan, C Das, M K B Whyte, C V E Powell,
R Primhak

\begin{abstract}
Background-The prevalence of childhood asthma is increasing but few studies have investigated trends in asthma severity. We investigated trends in asthma diagnosis and symptom morbidity between an eight year time period in a paired prevalence study. Methods-All children in one single school year aged 8-9 years in the city of Sheffield were given a parent respondent questionnaire in 1991 and 1999 based on questions from the International Survey of Asthma and Allergy in Children (ISAAC). Data were obtained regarding the prevalence of asthma and wheeze and current (12 month) prevalences of wheeze attacks, speech limiting wheeze, nocturnal cough and wheeze, and exertional symptoms.

Results-The response rates in 1991 and 1999 were $4580 / 5321(85.3 \%)$ and $5011 / 6021$ $(83.2 \%)$, respectively. There were significant increases between the two surveys in the prevalence of asthma ever $(19.9 \% v$ $29.7 \%$, mean difference $11.9 \%, 95 \%$ confidence interval (CI) 10.16 to $13.57, \mathrm{p}<0.001$ ), current asthma $(10.3 \%$ v $13.0 \%$, mean difference $2.7 \%$, 95\% CI 1.44 to 4.03 , p<0.001), wheeze ever $(30.3 \%$ v $35.8 \%$, mean difference $5.7 \%$, $95 \%$ CI 3.76 to 7.56 , p<0.001), wheeze in the previous 12 months $(17.0 \%$ v $19.4 \%$, mean difference $2.5,95 \%$ CI 0.95 to $4.07, \mathrm{p}<0.01$ ), and reporting of medication use $(16.9 \% v 20 \%$, mean difference $3.0 \%, 95 \%$ CI 1.46 to $4.62, \mathrm{p}<0.001$ ). There were also significant increases in reported hayfever and eczema diagnoses. Conclusions-Diagnostic labelling of asthma and lifetime prevalence of wheeze has increased. The current 12 month point prevalence of wheeze has increased but this is confined to occasional symptoms. The increased medication rate may be responsible for the static prevalence of severe asthma symptoms. The significant proportion of children receiving medication but reporting no asthma symptoms identified from our 1999 survey suggests that some children are being inappropriately treated or overtreated.

(Thorax 2001;56:312-314)
\end{abstract}

Keywords: asthma prevalence; children; diagnostic labelling; asthma treatment
Childhood asthma is common, especially in the UK. ${ }^{1}$ Several studies have reported increases in the prevalence of asthma and associated asthma morbidity symptoms using serial questionnaire surveys, ${ }^{2-7}$ but there has been controversy as to whether or not the prevalence of asthma is still increasing. The International Study of Asthma and Allergies in Childhood (ISAAC) questionnaire has been validated and has been used to investigate the prevalence of asthma throughout the world. ${ }^{1}$ We used a parent respondent questionnaire based on the ISAAC questions to investigate changes in asthma morbidity and treatment between 1991 and 1999 in two large cohorts of Sheffield children aged 8- 9 years.

\section{Methods}

The methods for the 1991 survey have been described previously ${ }^{8}$ and were replicated in the 1999 study. Briefly, all primary schools in Sheffield with year 4 pupils (aged 8-9 years) were approached for the 1999 survey. Individually labelled questionnaires were distributed to schools with instructions for children to take them home for their parents to complete. Nonresponders were sent a second identical questionnaire. The $\chi^{2}$ test was used to compare the differences between the surveys. The study was approved by the South Sheffield Research Ethics Committee and the Sheffield Education Authority.

\section{Results}

The results of the 1991 Sheffield schools survey have been reported previously. ${ }^{8}$ A total of 5011 of 6021 questionnaires (83.2\%) were returned from the 1999 survey. Of all responses where sex was specified, 2459 of $4912(50.1 \%)$ were male. 156 of 5011 respondents (3.1\%) indicated that they did not wish to take part in the survey. 4340 questionnaires were returned with all 15 questions completed (354 and 66 returned questionnaires had 14 of the 15 and 13 of the 15 questions completed respectively; a further 253 had fewer than 13 questions completed). Wherever possible answers from part completed questionnaires were included in the data analysis.

Symptoms reported in the preceding 12 months in the two surveys are compared in table 1. Although there were significant increases in the prevalence of wheeze and in 
Table 1 Prevalence of asthma and asthma morbidity symptoms in 1991 and 1999

\begin{tabular}{lllll}
\hline & \multicolumn{2}{l}{ Survey year } & & \\
\cline { 2 - 3 } & 1991 & 1999 & \% change (95\% CI) & p value \\
\cline { 2 - 3 } & & & & \\
Wheeze in previous 12 months & $771 / 4563(17.0 \%)$ & $932 / 4803(19.4 \%)$ & $+2.51(0.95$ to 4.07$)$ & $<0.01$ \\
Wheeze ever & $1376 / 4564(30.3 \%)$ & $1720 / 4810(35.8 \%)$ & $+5.66(3.76$ to 7.56$)$ & $<0.001$ \\
Current asthma & $466 / 4539(10.3 \%)$ & $624 / 4800(13.0 \%)$ & $+2.73(1.44$ to 4.03$)$ & $<0.001$ \\
Asthma ever & $811 / 4543(17.9 \%)$ & $1428 / 4806(29.7 \%)$ & $+11.86(10.16$ to 13.57$)$ & $<0.001$ \\
Wheeze attacks 1-3/year & $438 / 4560(9.6 \%)$ & $551 / 4766(11.6 \%)$ & $+1.96(0.71$ to 3.20$)$ & $<0.001$ \\
Wheeze attacks $>$ 3/year & $324 / 4560(7.1 \%)$ & $353 / 4766(7.4 \%)$ & $+0.30(-0.75$ to 1.35$)$ & NSD \\
Nocturnal wheeze at least once a week & $220 / 4548(4.8 \%)$ & $251 / 4757(5.3 \%)$ & $+0.44(-0.45$ to 1.33$)$ & NSD \\
Nocturnal cough at least once a week & $361 / 4435(8.1 \%)$ & $392 / 4784(8.2 \%)$ & $+0.05(-1.06$ to 1.17$)$ & NSD \\
Frequent exertional wheeze or cough & $174 / 4493(3.9 \%)$ & $217 / 4901(4.4 \%)$ & $+0.55(-0.25$ to 1.36$)$ & NSD \\
Speech limiting wheeze in last year & $136 / 4558(3.0 \%)$ & $125 / 4749(2.6 \%)$ & $-0.4(-1.04$ to 0.30$)$ & NSD \\
Eczema ever & $820 / 4523(18.1 \%)$ & $1497 / 4809(31.1 \%)$ & $+13.0(11.27$ to 14.72$)$ & $<0.001$ \\
Hayfever ever & $554 / 4508(12.3 \%)$ & $787 / 4802(16.4 \%)$ & $+4.1(2.68$ to 5.2$)$ & $<0.001$ \\
\hline
\end{tabular}

Data are shown as number/denominator (\%).

$\mathrm{CI}=$ confidence interval; NSD $=$ no significant difference .

*Defined by a positive answer to the question "Does your child have asthma at present?"

asthma diagnosis, the increase was confined to wheeze $\leqslant 3$ times yearly; more frequent symptoms were unchanged. Current wheeze, lifetime wheeze, current asthma (defined by a positive answer to the question "Does your child have asthma at present?"), and lifetime asthma were significantly higher in boys than in girls $(21.4 \%$ v $17.4 \% \quad(\mathrm{p}<0.001), 38.8 \% \quad v$ $33.0 \%(\mathrm{p}<0.001), 14.0 \%$ v $12.0 \%(\mathrm{p}<0.01)$, and $32.6 \%$ v $27.1 \%(\mathrm{p}<0.001)$, respectively).

Overall, in the 1999 survey 939 of 4700 children $(20.0 \%)$ were reported to be taking asthma medication compared with 768 of 4533 children $(16.9 \%)$ in 1991 (mean difference $3.0 \%, 95 \%$ confidence interval (CI) 1.46 to $4.62, \mathrm{p}<0.001$ ). Medication details for children with diagnosed asthma were available in 422 children in 1991 and 487 in 1999. Between surveys inhaled corticosteroid usage increased from $34.4 \%$ to $66.1 \%(\mathrm{p}<0.001)$, inhaled bronchodilator usage increased from $79.6 \%$ to $92.8 \%(\mathrm{p}<0.001)$, and sodium cromoglycate usage decreased from $23.2 \%$ to $3.7 \%(\mathrm{p}<0.001)$. Notably, in the 1999 survey we found that 249 of 931 children $(26.7 \%)$ receiving asthma medication reported no wheezing in the last 12 months; even in those taking regular inhaled corticosteroids this figure was $19.4 \%$. A further $192(20.6 \%)$ children receiving asthma medication were reported not to have a current diagnosis of asthma.

\section{Discussion}

We have shown increases in the prevalences of reported wheeze, diagnosed asthma, and reported eczema and hayfever in 8-9 year old Sheffield children between 1991 and 1999. The point prevalence of wheeze in the past 12 months increased by an absolute value of $2.4 \%$ over 8 years. This increase could be due to methodological or response variations, changes in parental or doctor behaviour, in either labelling or treatment, or a genuine change in inherent susceptibility or in environmental factors. We have used consistent methodology and achieved good response rates, so it is unlikely that these differences could be due to differences in methodology or population characteristics. Similarly, the response rates of $85.3 \%$ in 1991 and $83.3 \%$ in 1999 suggest that any bias due to non-responders is minimal.

Our observations are supported by a number of previous studies. ${ }^{2-7}$ Burr et al studied two cohorts of 12 year old children using question- naire and exercise provocation tests 15 years apart between 1973 and $1988 .^{2}$ The point prevalence of "wheeze ever" increased from $17 \%$ to $22 \%$ and "current asthma" from $4 \%$ to $9 \%$. Between 1964 and 1989 asthma in Aberdeen school children increased from $4.1 \%$ to $10.1 \%{ }^{4}$ and a repeat survey in 1994 reported a further rise to $19.6 \%$ with, in contrast to our study, an increase in asthma severity. ${ }^{6}$ Venn et al reported cross sectional survey data between 1988 and 1995 which showed absolute increases in lifetime and 12 month wheeze prevalences and diagnosed asthma in children aged $4-11$ years. ${ }^{7}$ These studies have suggested that the asthma prevalence rate has continued to rise and that this cannot be ascribed solely to diagnostic labelling, in contrast to the observations of Hill et al. ${ }^{3}$ Magnus and Jaakkola consider that information biases and changes in diagnostic labelling might explain the increases in wheeze and asthma seen in other repeated surveys and have suggested that "objective measures" should be used. ${ }^{9}$ Since we have previously shown that the free running exercise test had much poorer reproducibility than questionnaire data, ${ }^{10}$ we decided not to include such a measure in our initial survey.

Our results suggest that the increase in wheezing is largely due to infrequent and minor wheezing symptoms. This might be because of increased perception or reporting of wheezing, or a genuine increase in minor wheezing. The prevalence of diagnosed eczema and hayfever in Sheffield has also increased significantly, in keeping with other studies. ${ }^{24}$ This continuing increase in atopic disease may also be contributing to the rising prevalence of wheeze. An alternative explanation for the increase in wheeze and asthma apparently being confined to mild cases could be the increased use of inhaled corticosteroids. This is supported by the increase in reported medication usage in asthmatic children. In a population prevalence study in children aged 7.5-8.5 years from a single London borough, the prevalence of frequent wheeze attacks was unchanged between 1978 and 1991 while markers of severe asthma fell over the same period. ${ }^{5}$ The authors concluded that this finding was due to an "improvement in treatment received by wheezy children". However, our findings suggest that at least some of the 
apparent increase may be due to changes in the perception of minor wheezing symptoms.

A final point to be noted in our results is the high use of asthma medication in children who lack either a recent history of wheeze or a diagnosis of asthma. This suggests that asthma is being overtreated or overdiagnosed in a significant number of children and reinforces the need to review and step down asthma treatment in children when symptom control is adequate.

In conclusion, our results suggest an increase in the prevalence of both diagnosed asthma and current wheeze between 1991 and 1999 in 8-9 year old Sheffield children. This appears to be due to the combination of an increase in minor wheeze symptoms and a rise in diagnostic labelling. We found no significant change in asthma severity. Although this may be due in part to an increase in prescription of antiinflammatory medication, the large number of children without current wheeze who are receiving asthma medication suggests that there may be significant overtreatment of children with such drugs.

We would like to thank the schools and parents who contributed to the study and Clare Billings, Simon Billings, and Sarah Primhak for their help with data input.
Funding: GNMK, RD, and CG received salary support from GlaxoWellcome (for an unrelated clinical study) and AP from the Special Trustees of the former United Sheffield Hospitals. Conflict of interests: none.

1 The International Study of Asthma and Allergies in Childhood (ISAAC) Steering Committee. Worldwide variation in prevalence of symptoms of asthma, allergic rhinoconunctivitis, and atopic eczema: ISAAC. Lancet 1998;351:1225-32.

2 Burr ML, Butland BK, King S, et al. Changes in asthma prevalence: two surveys 15 years apart. Arch Dis Child 1989;64:1452-6.

3 Hill R, Williams J, Tattersfield A, et al. Change in use of asthma as a diagnostic label for wheezing illness in schoolchildren. BMF 1989;299:898

4 Ninan TK, Russell G. Respiratory symptoms and atopy in Aberdeen schoolchildren: evidence from two surveys 25 years apart. BMF 1992;304:873-5.

5 Anderson HR, Butland BK, Strachan DP. Trends in prevalence and severity of childhood asthma. BMF 1994;308: $1600-4$

6 Omran M, Russell G. Continuing increase in respiratory symptoms and atopy in Aberdeen schoolchildren. BMF 1996;312:34.

7 Venn A, Lewis S, Cooper M, et al. Increasing prevalence of wheeze and asthma in Nottingham primary schoolchildren 1988-1995. Eur Respir 7 1998;11:1324-8.

8 Powell CV, Primhak RA. Asthma treatment, perceived respiratory disability, and morbidity. Arch Dis Child 1995;72:209-13.

9 Magnus P, Jaakkola JJ. Secular trend in the occurrence of asthma among children and young adults: critical appraisal of repeated cross sectional surveys. BMF 1997;314:1795-9.

10 Powell CV, White RD, Primhak RA. Longitudinal study of free running exercise challenge: reproducibility. Arch Dis Child 1996;74:108-14.
Manchester Adult Cystic Fibrosis Unit, South Manchester University Hospitals NHS Trust, Wythenshawe Hospital, Manchester M23 9LT, UK C S Haworth A W Horrocks A K Webb

Department of Medicine, University of Manchester, Manchester Royal Infirmary, Manchester M13 9WL, UK

P L Selby

E B Mawer

Clinical Radiology, Imaging Science and Biomedical Engineering, University of Manchester, Manchester M13 9PT, UK

J E Adams

Correspondence to: Professor A K Webb the5webbs@hotmail.com

Received 5 June 2000 Returned to authors 3 October 2000 Revised version received 8 November Accepted for publication 18 December 2000

\title{
Effect of intravenous pamidronate on bone mineral density in adults with cystic fibrosis
}

\author{
C S Haworth, P L Selby, J E Adams, E B Mawer, A W Horrocks, A K Webb
}

\begin{abstract}
Background-Low bone mineral density (BMD) is prevalent in adults with cystic fibrosis. The aim of this study was to assess the effect of intravenous pamidronate on BMD in these subjects.

Methods-Patients were invited to participate if they had a BMD Z score of -2 or less in the lumbar spine, proximal femur, or distal forearm. Patients were randomised to receive either $30 \mathrm{mg}$ intravenous pamidronate every 3 months $+1 \mathrm{~g}$ calcium daily (pamidronate group) or $1 \mathrm{~g}$ calcium daily (control group). All pancreatic insufficient patients were prescribed oral vitamin $D$ supplements.

Results-After 6 months of treatment the pamidronate group $(n=13)$ showed a significant increase in absolute BMD compared with the control group $(n=15)$ in the lumbar spine (mean difference $5.8 \%$ (CI $2.7 \%$ to $8.9 \%$ )) and total hip (mean difference $3.0 \%$ (CI $0.3 \%$ to $5.6 \%$ )). However, the pamidronate group showed a reduction in BMD compared with the control group in the distal forearm (mean differ-
\end{abstract}

ence $-1.7 \%$ (CI $-3.7 \%$ to $0.3 \%)$ ). The use of pamidronate was associated with a high incidence of bone pain in noncorticosteroid treated individuals.

Conclusion-Intravenous pamidronate increases axial BMD in adults with cystic fibrosis, but the high incidence of bone pain associated with this treatment might limit its use.

(Thorax 2001;56:314-316)

Keywords: cystic fibrosis; bone mineral density; osteoporosis; pamidronate; bisphosphonates

Low bone mineral density (BMD) is prevalent in adults with cystic fibrosis. ${ }^{12}$ Biochemical and histomorphometric studies suggest that osteoblastic activity is reduced and that osteoclastic activity is increased. ${ }^{3}$ As bisphosphonates are potent inhibitors of osteoclastic bone resorption, they are a logical therapeutic choice to treat adult cystic fibrosis patients with low BMD. The aim of this study was to assess the effect of intravenous pamidronate on BMD in adults with cystic fibrosis. 


\section{Methods}

STUDY POPULATION

In 1998, after 1 year of follow up in a longitudinal BMD study, patients with cystic fibrosis aged 18 years of over who had a BMD Z score of -2 or less in the lumbar spine, proximal femur, or distal forearm were offered the option of participating in this treatment trial. Thirty one of the 44 eligible patients (70\%) agreed to participate.

All patients were attending the Manchester Adult Cystic Fibrosis Unit and the diagnosis of cystic fibrosis was confirmed by gene analysis. The study was approved by the South Manchester research ethics committee and each patient provided written informed consent.

\section{STUDY DESIGN}

Patients were randomised to receive for a 1 year period either $30 \mathrm{mg}$ intravenous pamidronate (Aredia Dry Powder, Novartis, Camberley, Surrey, UK) every 3 months $+1 \mathrm{~g}$ calcium daily (Calcichew Forte, Shire Pharmaceuticals, Andover, Hants, UK) or $1 \mathrm{~g}$ calcium daily. All pancreatic insufficient patients were prescribed vitamin D supplements (900 IU daily) long term.

BMD was measured in the lumbar spine and proximal femur (total hip) by dual energy $x$ ray absorptiometry (QDR 4500 Acclaim densitometer, Hologic, Waltham, Massachusetts, USA) and in the distal forearm by single energy $x$ ray absorptiometry (Osteometer DTX-100 densitometer, Osteometer Meditech, Rødovre, Denmark) at the beginning and end of the study. The short term departmental precision for each bone densitometry technique was derived from repeated measurements in 10 subjects. Expressed as a coefficient of variation $(\mathrm{CV})$, the short term precision was $1.1 \%$ in the lumbar spine, $1.3 \%$ in the total hip, and $1.0 \%$ in the distal forearm. The long term precision was derived from scanning an appropriate phantom, giving a CV of $0.63 \%$ for the Osteometer DTX-100 forearm scanner and $0.22 \%$ for the Hologic QDR 4500 scanner. The baseline BMD results were expressed as $Z$ scores and the reference data were provided by the densitometer manufacturers. The percentage change in BMD over the treatment period was calculated from the absolute BMD values $\left(\mathrm{g} / \mathrm{cm}^{2}\right)$ recorded at the beginning and end of the study.

STATISTICAL ANALYSIS

Data were analysed using SPSS version 7.0 (SPSS Inc, Chicago, Illinois, USA). The continuous variables were normally distributed and summarised using the mean (SD) values. Differences between groups were identified using the unpaired Student's $t$ test.

Table 1 Percentage change in bone mineral density $\left(\mathrm{g} / \mathrm{cm}^{2}\right)$ after 6 months of treatment

\begin{tabular}{lllll}
\hline & $\begin{array}{l}\text { Pamidronate group } \\
(n=13)\end{array}$ & $\begin{array}{l}\text { Control group } \\
(n=15)\end{array}$ & $\begin{array}{l}\text { Mean }(95 \% \text { CI) difference } \\
\text { in changes between groups }\end{array}$ & p value \\
\hline Lumbar spine & $4.1 \%$ & $-1.7 \%$ & $5.8 \%(2.7 \%$ to $8.9 \%)$ & 0.001 \\
Total hip & $1.7 \%$ & $-1.3 \%$ & $3.0 \%(0.3 \%$ to $5.6 \%)$ & 0.029 \\
Distal forearm & $-1.1 \%$ & $0.6 \%$ & $-1.7 \%(-3.7 \%$ to $0.3 \%)$ & 0.095 \\
\hline
\end{tabular}

\section{Results}

PATIENT CHARACTERISTICS

Thirty one patients were recruited to the trial, none of whom had received bone sparing agents in the past. Fifteen patients were randomised to the pamidronate + calcium group (pamidronate group) and 16 patients were randomised to the calcium only group (control group). Three patients did not complete the study; one patient in each group died of respiratory failure and one patient in the pamidronate group received a double lung transplant.

On recruitment to the study the mean (SD) age, body mass index, and forced expiratory volume in one second in the pamidronate group compared with the control group were: 25.1 (6.3) v 26.9 (5.4) years (NS); $20.3(2.4) v$ $21.8(2.9) \mathrm{kg} / \mathrm{m}^{2}$ (NS); and 49.0 (18.1) $v 52.7$ (22.6)\% predicted (NS), respectively. One patient in the control group was pancreatic sufficient. All other patients were prescribed long term oral vitamin D supplements (900 IU daily). On recruitment to the study the mean (SD) 25-hydroxyvitamin D level in the pamidronate group was $22.4(18.5) \mathrm{ng} / \mathrm{ml}$ compared with $19.5(10.5) \mathrm{ng} / \mathrm{ml}$ in the control group (NS). Of the patients who completed the trial, four in the pamidronate group and nine in the control group required one or more courses of oral corticosteroid therapy during the treatment period.

BONE MINERAL DENSITY

The baseline BMD Z scores in the pamidronate and control groups were $-2.2(1.1) v-2.3$ (0.9) in the lumbar spine (NS), $-2.0(0.9) v$ $-1.6(0.7)$ in the total hip (NS), and $-1.7(0.9)$ $v-1.4(0.8)$ in the distal forearm (NS). The percentage change in absolute BMD $\left(\mathrm{g} / \mathrm{cm}^{2}\right)$ at each skeletal site during the treatment period is shown in table 1.

\section{ADHERENCE}

Of the patients who completed the trial, all those in the pamidronate group received two pamidronate infusions during the 6 month treatment period and the mean (SD) adherence with calcium supplementation, calculated by a residual tablet count, was $75(27) \%$ in the pamidronate group and $76(26) \%$ in the control group (NS).

ADVERSE EVENTS

As previously reported, ${ }^{5} 11$ of the 15 patients randomised to receive intravenous pamidronate developed moderate to severe bone pain after the first dose. None of the patients who developed bone pain were taking oral corticosteroid therapy at the time of pamidronate infusion. ${ }^{6}$ However, three of the four patients $(p=0.009)$ who were pain free had been taking 10-15 mg prednisolone long term (two for unstable lung disease and one for allergic bronchopulmonary aspergillosis). The pattern of bone pain was less consistent following the second pamidronate infusion; most patients experienced pain, but it was of a lesser severity. None of the patients in the control group developed bone pain. The duration of the trial 
was shortened from 1 year to 6 months because of the adverse events.

\section{Discussion}

In adult patients with cystic fibrosis related low $\mathrm{BMD}$ intravenous pamidronate + oral calcium resulted in a significant increase in lumbar spine and total hip BMD compared with oral calcium alone. A significant side effect was bone pain in non-corticosteroid treated individuals. ${ }^{56}$

This is the first study to evaluate the efficacy of bisphosphonate treatment in nontransplanted cystic fibrosis patients with low BMD. An intravenous bisphosphonate was chosen to circumvent the upper gastrointestinal side effects and poor absorption associated with oral bisphosphonates. After 6 months of treatment BMD in the lumbar spine increased by $4.1 \%$ in patients receiving pamidronate + calcium compared with a reduction of $1.7 \%$ in patients receiving calcium alone. This $5.8 \%$ difference between treatment groups compares favourably with the use of alendronate in postmenopausal women in whom there was an $8.8 \%$ difference in lumbar spine BMD between treatment and placebo groups after 3 years of follow up. ${ }^{7}$ In the present study BMD also increased significantly in the total hip, but there was a reduction in forearm BMD. Similar divergent changes in regional BMD have been reported with the short term use of intravenous pamidronate in Paget's disease. ${ }^{8}$ A subsequent study in this patient group showed that calcium and calcitriol prevented peripheral bone loss after intravenous pamidronate. ${ }^{9}$ This emphasises the importance of optimising vitamin D levels before starting bisphosphonate treatment.

This study has a number of limitations. Firstly, the data must be interpreted in the context of the small number of patients enrolled and the shortened period of follow up. Secondly, the BMD results might have been influenced by the greater use of corticosteroids in the control group than in the treatment group. Thirdly, sex might have influenced the results as there were a disproportionate number of female patients randomised to the pamidronate group compared with the control group. Despite the above reservations, a recent study using intravenous pamidronate in posttransplant patients with cystic fibrosis reported similar treatment responses. ${ }^{10}$ Together these studies emphasise that low BMD is a continuum in cystic fibrosis patients before and after transplantation and that it is amenable to treatment.

In conclusion, intravenous pamidronate caused a rapid increase in axial BMD in adult patients with cystic fibrosis, but the high incidence of bone pain associated with this intervention might limit its use. This study suggests that bisphosphonates may have a role in the management of cystic fibrosis related low BMD. Further studies are required to evaluate their long term safety and efficacy in preventing fragility fractures.

This study was supported by a grant from the Cystic Fibrosis Research Trust, UK. The authors are indebted to D Ledgeton,
M Hodgkinson, C Alsop, and R Larder for performing the bone M Hodgkinson, C Alsop, and
densitometry measurements.

1 Haworth CS, Selby PL, Webb AK, et al. Low bone mineral density in adults with cystic fibrosis. Thorax 1999;54:961-7.

2 Conway SP, Morton AM, Oldroyd B, et al. Osteoporosis and osteopenia in adults and adolescents with cystic fibrosis: . Thorax 2000;55:798: prev

3 Baroncelli GI, De Luca F, Magazzu G, et al. Bone demineralization in cystic fibrosis: evidence of imbalance between bone formation and degradation. Pediatr Res 1997;41:397bone for

4 Haworth CS, Webb AK, Egan JJ, et al. Bone histomorphometry in adult patients with cystic fibrosis. Chest 2000;118: $434-9$

5 Haworth CS, Selby PL, Webb AK, et al. Severe bone pain after intravenous pamidronate in adult patients with cystic fibrosis. Lancet 1998;352:1753-4.

6 Haworth CS, Selby PL, Webb AK, et al. Oral corticosteroids and bone pain after pamidronate in adults with cystic fibrosis. Lancet 1999;353:1886.

7 Liberman UA, Weiss SR, Broll J, et al. Effect of oral alendronate on bone mineral density and the incidence of fractures in post menopausal osteoporosis. $N \mathrm{Engl} F \mathrm{Med}$ 1995;333:1437-43.

8 Price RI, Gutteridge DH, Stuckey BGA, et al. Rapid, divergent changes in spinal and forearm bone density following short-term intravenous treatment of Paget's disease with short-term intravenous treatment of Paget's disease with

9 Stewart GO, Gutteridge DH, Price RI, et al. Prevention of appendicular bone loss in Paget's disease following appendicular bone loss in Paget's disease following treatment with

10 Aris RM, Lester GE, Renner JB, et al. Efficacy of pamidronate for osteoporosis in patients with cystic fibrosis following lung transplantation. Am $\mathcal{F}$ Respir Crit Care Med 2000; 162:941-6. 